\title{
Accessible polyvocality and paired talk: how family therapists talk positive connotation into being
}

Williams, L

http://hdl.handle.net/10026.1/4158

10.1111/1467-6427.12096

Journal of Family Therapy

Wiley

All content in PEARL is protected by copyright law. Author manuscripts are made available in accordance with publisher policies. Please cite only the published version using the details provided on the item record or document. In the absence of an open licence (e.g. Creative Commons), permissions for further reuse of content should be sought from the publisher or author. 


\title{
Accessible Polyvocality and Paired Talk: How Family Therapists Talk Hope into Being
}

\begin{abstract}
In this paper we identify one particular way in which the reflecting team process is used by family therapists. We demonstrate that reflecting teams draw upon occasions in the main session where positive connotation is constituted in talk by family therapists. This positivity is then intensified and extended in the reflecting session. This analysis identified positive connotation as a device by which hopeful orientation is established. Videos of family therapy sessions were obtained and transcripts of these sessions made. 2 paired excerpts dealing with hope and positivity were identified and conversation analysis was used to gain insight into the organisation and function of the institutional talk of family therapy. In addition, the reflecting session in family therapy sessions was analysed and 'second versions' of therapist main session interventions were identified. Main session interpretations of talk and second versions were found to work together as a resource for the construction of hope in family therapy.
\end{abstract}

Conversation analysis (CA) is a helpful methodology for evaluating the process of family therapy and the dynamics of professional practice, and can provide insight into how professional concepts act as resource for 'doing family therapy'. CA allows us to see how hope is facilitated and co-constructed by family therapists as they align with positive connotation by taking up and enacting a positive interpretation of family relationships. 


\section{Introduction}

\section{The reflecting team and 'accessible polyvocality'}

The development of the reflecting team process (RTP) within family therapy is credited to Andersen (1987) and the principles of this approach are now widely established within family therapy practice. In their survey of 130 systemic practitioners in the UK, Willott, Hatton \& Oyebode (2012) reported that 92 per cent of respondents used teamwork for around a third of their therapy time, with reflecting team practices being the most commonly used approach.

Key to the RTP proposed by Andersen is the revisiting of the main family therapy session in a review conducted entirely by the observing therapists. According to Andersen and others, this practice is advantageous because it puts the reflecting team in a position where they can explore the constructs of individual family members, their non-verbal processes and hypothetical future scenarios, all in a respectful and positive manner, without the direct participation of the family members themselves. Furthermore, the work of the reflecting team takes the focus off the family members, so that they can benefit from the therapeutic process without the pressure of being part of it.

A theme in the work of the reflecting teams is sharing alternative versions of a situation or problem to encourage a shift in perspective within the overhearing family. Willott et al (2012) state that families may perceive a problem from only one perspective, which results in a restricted opportunity for change and a hopeless position resulting from a 'problem-saturated narrative'. By engaging in 'accessible polyvocality', the vocalisation of alternative views of problems, models differing perspectives available to family participants. 
These practices are central to the reflecting team process and uniquely distinguish family therapy from other forms of 'talking therapy'. RTP enables family therapists to work further on the talk from the main session, and in doing so, produce second or further versions of events relevant to illuminating the family's problems. This accessible polyvocality can incorporate aspects such as the value of individuals' relationships to each other, or thoughts about each other framed within positive connotation that contributes to a hopeful outlook for the family. As Willott et al. say: "Accessible polyvocality is more than a useful technique to be employed in particular situations: it is central to the whole approach." (2012, p. 184)

\section{Hope and family therapy}

Although it is given the term polyvocality,' the reflecting session is oriented toward producing a particular kind of version of the family's problems, namely one which offers hope of resolution (Willott et. al, 2010). This focus on hope or optimism is captured in Andersen's (1987) own narrative of the discovery of the therapeutic power of the reflecting session:

"Several years ago we were supervising a young family interviewer who was repeatedly drawn into the pessimism of the family he was interviewing. The three of us who were observing from behind the screen called him out three times to suggest more optimistic questions to him, but each time the family pulled him back into their pessimism. We knew that there was a set of microphones and speakers in both rooms and asked if the family and interviewer would like to listen to the three of us talk. The lighting and the sound were switched, and the family and interviewer watched and listened to 
the team reflecting in a more positive fashion about the family." (Andersen, 1987, p. 415)

Positive connotation is specifically relevant to the movement toward a more hopeful outlook within family therapy practice (Jones, 1993). Positive connotation normally requires the family therapist to comment positively on individual behaviour in the light of the family system. For example, a child's angry outburst during a session can be interpreted as demonstrating a family characteristic where expression of feelings is acceptable - a positive connotation of the family relationships. The value of relationships between family members is therefore emphasised. Specifically positive connotation opens up new ways of considering problematic issues in the family which can encourage a more hopeful outlook for the family.

\section{Conversation Analysis and Family Therapy Practices}

Willott et al. (2012) conducted a comprehensive search of the literature relating to reflecting team practice, and found very little research which investigated the role and organisation of the reflecting team. They suggest that consideration of the 'possibly taken for granted' and consequently less apparent therapeutic processes has been particularly lacking in relation to the family therapy reflecting team. Therefore, this current study of the reflecting team practice and the development and extension of hope within family therapy is an initial attempt to address this lacuna. Moreover, the research on hope that has been conducted to date has predominantly been based on retrospective evaluations of the practice as a particular type of therapy intervention. This approach to evaluation sidesteps the issue of what happens in 'live' family therapy situations. As a consequence it is difficult to assess how hope as a concept, and the positive connotation that it is grounded in, is deployed in family therapy practice and what consequentially flows from its 
deployment. Furthermore, retrospective reporting of hope limits our understanding of how it is manifested through interaction and thus how hopeful meanings are produced and made relevant by therapists.

Our own approach to understanding family therapy and in particular how reflecting team practice works, has been to adopt a Conversation Analytic (CA) perspective (Sacks, 1992; Schegloff, 2007; Sidnell, 2010). CA is a social constructionist methodology and hence for many within the CA field, psychological constructs such as 'hope' are analysts' resources which are deployed to further the business of the therapy rather than ontologically distinct mental entities (cf. Auburn 2005; Edwards \& Potter, 2005; O'Reilly, 2005). CA examines the sequential organisation of talk on a turn-by-turn basis and focuses on how particular projects, such as positive connotation, are accomplished jointly by the participants.

\section{Professional Stocks of Interactional Knowledge}

According to Perakyla \& Vehvilainen (2003) many professional areas incorporate normative models of how the professional should interact with clients in order to operationalize the theoretical models or frameworks which underpin their professional activity. They call these models professional 'Stocks of Interactional Knowledge' (SIK) and cite as a particular example Family Systems Theory, arguing that aspects of this system such as co-counsellor interventions are an important component of its professional SIK. These authors argue that CA can open up SIK's to identify anomalies, gaps or contradictions showing how such knowledge frameworks form a resource for practitioners. This is achieved in the following ways relevant to the current study. Firstly, CA can add additional detail to SIKs by highlighting more complex and interactional dimensions of talk, moving beyond prior established formats and norms. Secondly, CA can introduce a 'new dimension' into 
understanding institutional talk as elements other than the stated aims of interactional knowledge can be identified. For example, alternative aspects of the family therapy reflecting session can be illuminated as significant in areas not stated in textbooks or training manuals.

This study uses CA to examine RTP practice within Family Therapy. We have focused on a distinctive manifestation of RTP which we have termed 'paired talk'. Paired talk was defined as occasions where a family issue which had formed the basis for commentary in the main session was the focus of further analysis and interpretation in the reflecting session. A particular issue is introduced by the family and becomes the object of attention by the therapist during the main session; the same issue is then focused on and reworked (usually with the objective of providing an optimistic version) by the therapists in the reflecting session. This device is an institutionally unique feature of RTP and can be considered to form part of family therapy's professional SIK. Our aim is to explicate in some detail how this aspect of RTP is deployed in practice and what functions it performs in the context of the family therapy session. 


\section{Method}

Data was obtained from a from service which offers a group work programme using systemic family therapy to families. Families can self-refer or, as is more normal, are referred by a wide range of statutory or voluntary sector organisations. The number of sessions attended by each family varies depending on the level of need presented. Five separate families were recruited to this study and video recordings of the family sessions were used. These are made by the service as standard practice for reference, training and development purposes. As part of the approved ethical protocol full consent was gained from all family participants separately including children and young people for use of these recordings for this research.

Family therapy sessions were normally conducted with two interviewing therapists. In addition, there were either one or two other therapists present in the room observing but not participating in the main session. The reflecting process involved the observing therapists (though there were occasions when the reflecting team consisted of one observing therapist and the interviewing therapist) who engaged in a process of verbal reflection at the end of the main therapy session. For each family a one hour session was selected for analysis which included the reflecting session; this amounted to approximately 5 hours of recorded material.

Over all sessions three different family therapists (one male, two female), five parents (all mothers), one grandparent and 8 children including siblings (both male and female) participated in the sessions.

\section{Analytic procedure}

Orthographic transcriptions of the main sessions and reflecting sessions were initially made and at this stage fully anonymised. The identification of 'paired talk' proceeded 
as a two-step process. First, occasions were identified when a family problem in the therapy session was introduced by the participants and where the therapist then produced a positive interpretation of this issue. Second, such occasions were reviewed and compared to the talk in the reflecting session. When talk from the main session was referenced by the same themes, topics or words in the reflecting session this indicated a paired relationship between the two sections of the family therapy. A robust corpus of exemplars of paired talk was assembled. Across the five hours of recorded data, we identified 16 occasions of paired talk. Each instance of paired talk was then fully transcribed using Jeffersonian transcription conventions (see Appendix).

The analysis focused on the social organisation of these episodes of paired talk; we firstly identified how the participants produced versions of the family problems in the main session. We then consider how these versions are revisited and reworked in the reflecting session. We present two exemplars of paired talk; each exemplar is comprised of two excerpts: one from the main session and its revisiting in the reflecting session. 


\section{Analysis}

The first excerpt shows two main aspects of paired talk. First how the interaction between clients and therapists in the main session transforms a potential difficulty within the family into one which has a positive connotation. Second this same difficulty is revisited in the RTP session and built on to reinforce its positivity. We draw attention here to the social organisation of the talk which gives this second version of the issue raised particular resonance as an authoritatively endorsed interpretation and resolution of the difficulty. The analysis of this excerpt displays how two features of family therapy practice are manifested: positivity and accessible polyvocality.

\section{Excerpt 1}

The main session talk (1A) shows a canonical therapeutic practice (Antaki et al.): a formulation which here transforms the talk to emphasise the positive side of the relationship between $Y$ (the young person) and her stepfather. At the start of this extract Y's mother has provided an assessment of how the stepfather would react to Y's contact with her biological father (lines 1-2). This version potentially removes one of the salient barriers to the contact between $Y$ and her biological father. Assessments normatively make relevant a next response of alignment or disalignment with the stance displayed. In CA terms, alignment is typically the preferred response whereas disalignment is dispreferred. Y's response displays a number of markers indicative of dispreferment: a short delay before responding (line 3), pro-forma agreement followed by the contrastive 'but' (line 4). Overall this response is designed to resist aligning with the mother's assessment. When people make epistemic claims, as the mother has done here with a straightforward 
declarative sentence, the nature of the claim and the rights to make that claim are 'patrolled and defended by individuals' (Heritage \& Raymond, 2005: 34). Y's response displays her equivalent right to make claims about her 'dad's' feelings which are in marked contrast to the mother's claims. She then set out her own counter claim which she has equal epistemic rights to make. There follows an impasse with T2 producing a sequence closing third response ('mm'). This response is an acknowledgement token which noticeably does not endorse Y's claim about the father.

There follows a lapse in the talk (line 9) and it is at this point that the therapist produces a formulation. Formulations as discursive devices are dominantly retrospective. They achieve a particular sense of the talk up to that point through three features: selection, transformation and deletion of aspects of the prior talk. In this way a formulation maintains a relationship with the prior talk while simultaneously changing the direction or emphasis of the talk. Here the therapist produces a radical transformation by shifting the emphasis to the father's overriding feelings toward his stepdaughter rather than the specific reaction to her contact with her biological father and these overriding feelings of love and care are treated as inferences available from the negative reaction identified by the daughter. Furthermore this inference is treated as something obviously available to the daughter as well (line 10: 'so you must know').

Formulations prefer agreement as responses and indeed the daughter produces a series of agreement tokens (yeah, nods) throughout the unfolding of this formulation. It is reinforced by the second therapist who also produces an agreement at the conclusion of the formulation.

This intervention by the therapist achieves a range of outcomes: 
i. It aligns with the mother's position and against the daughter's by suggesting that the barriers to contact are not as salient as the daughter claims.

ii. It achieves positivity through its emphasis on the dominantly positive feelings that the step father has toward his daughter, and that the negative traits identified by the daughter are to be treated as signs of his love and care.

In the reflecting session (1B), this interpretation is extended and emphasises an unequivocally positive connotation drawn from talk about familial conflict and disagreement. 


\section{Paired Talk - Excerpt 1}

( $P$ - mother; $Y$ - young person; T1 - therapist 1; T2 - therapist 2)

In this extract the family is discussing the contact between the female young person $(\mathrm{Y})$ and her biological father and the reaction to this meeting by Y's stepfather. 'Dad' referenced in 1A line 2 is Y's stepfather.

\begin{tabular}{|c|c|}
\hline 1A Main Session Therapist Intervention & 1B Reflecting/Second Version \\
\hline 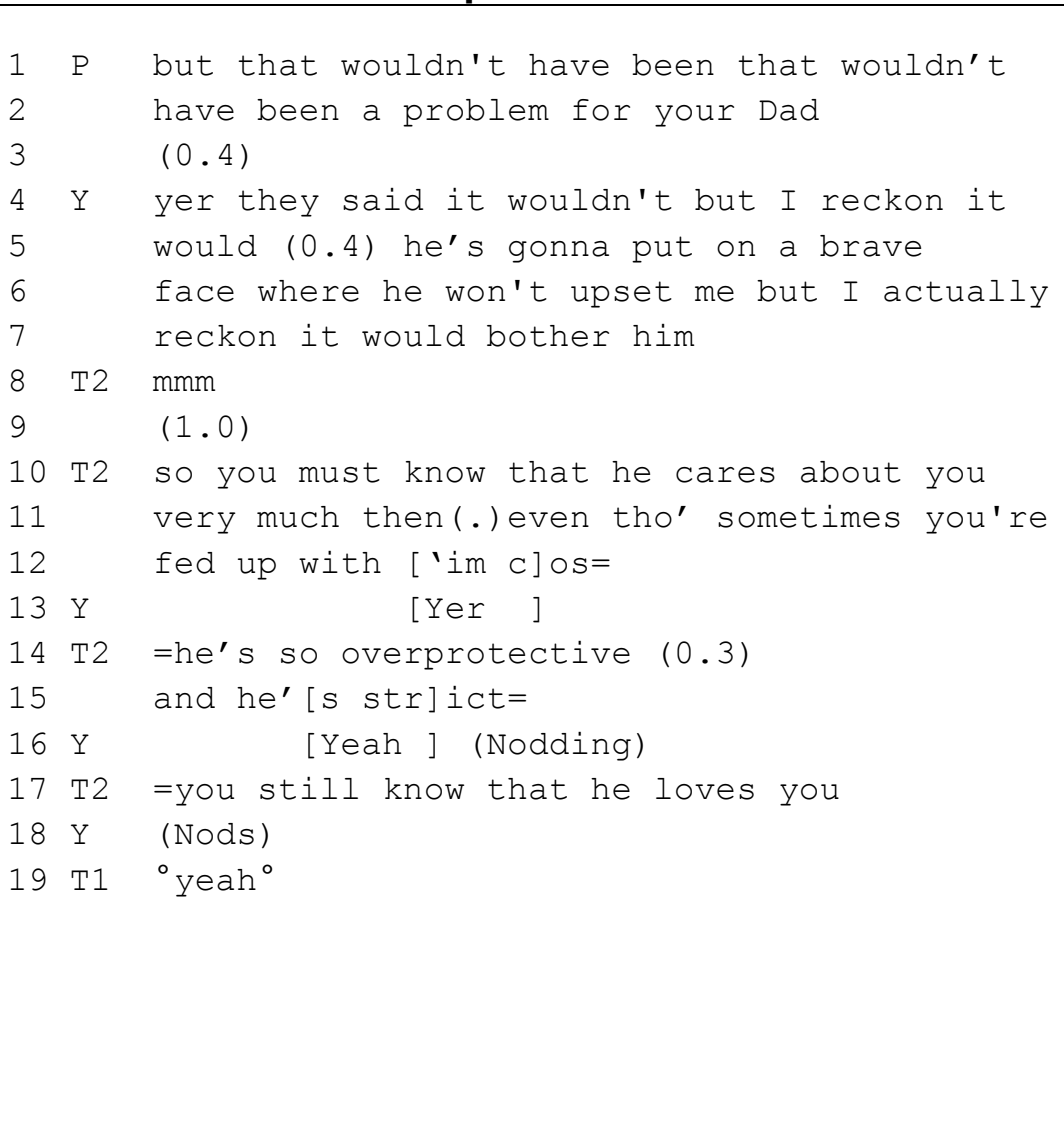 & 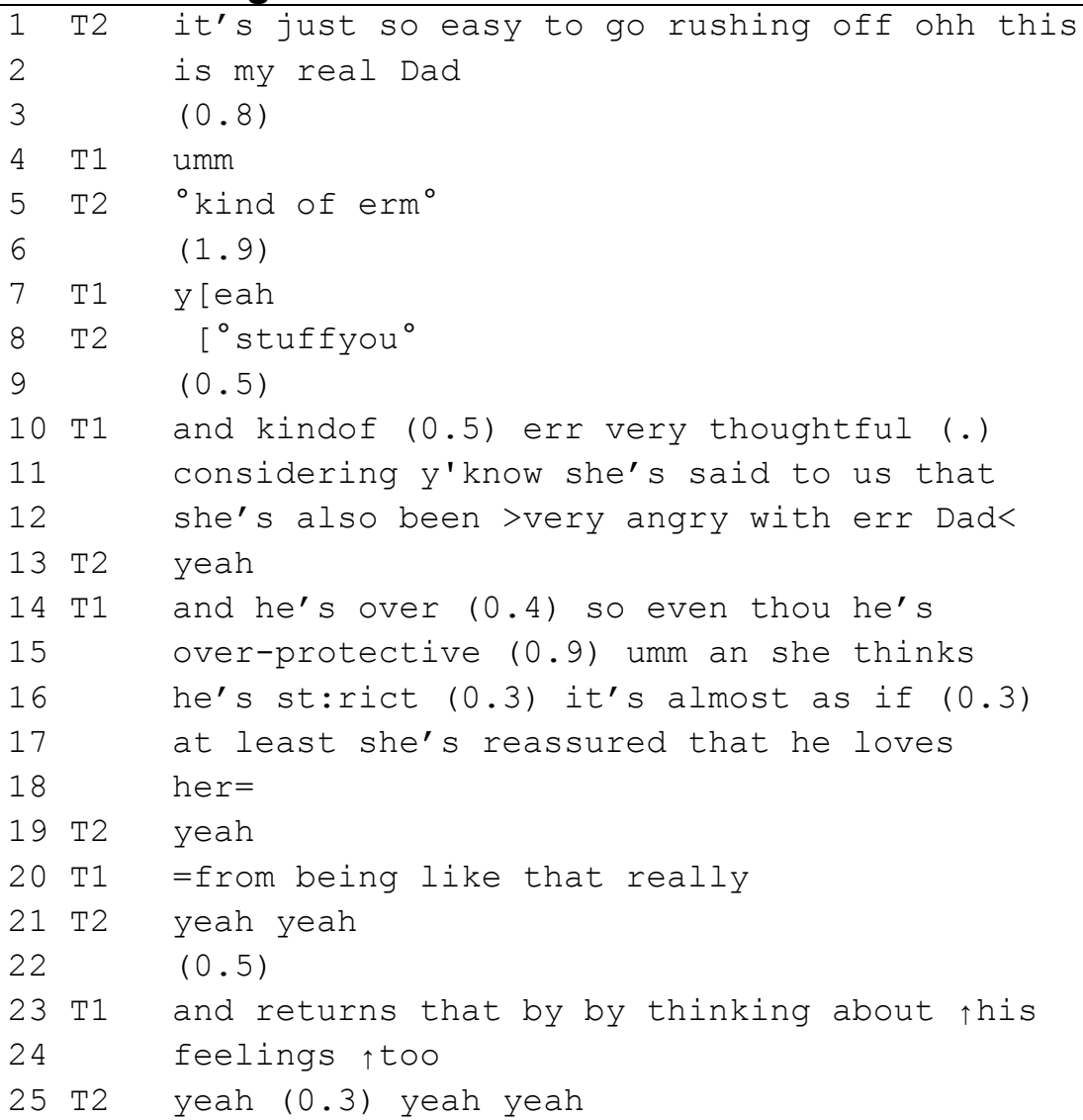 \\
\hline
\end{tabular}




\begin{tabular}{|l|l|l|}
\hline & $\begin{array}{ll}26 & \text { T1 which is really nice } \\
27 & \text { T2 yeah }\end{array}$ \\
\hline
\end{tabular}


The shift to the reflecting session is marked for the participants by a radical change in physical orientation as the therapists move to face one another and put the family members into the position of observers. The interaction then proceeds exclusively between the therapists. This change in orientation is integral to the constitution of this moment as the reflecting session.

The second version in extract 1B captures and extends the meaning of the talk from the main session $(1 \mathrm{~A})$ in the following ways:

i. Positivity is worked up collaboratively by the two therapists displaying a consensus about the stance that the young person is presumed to take to the problem situation with her step-father.

ii. The same words and phrases are re-used thus anchoring the second version to the main session talk and adding to the authenticity of the second version as a return to the issues identified in the main session.

iii. A positive orientation is extended by using stronger terminology than that used by the therapist in the main session.

iv. Rationalisation for a previously resisted course of action.

The RTP extract begins with T2 describing a potential course of action which Y might undertake as a response to the problem of meeting up with her natural father. This course of action is presented as one which is recognisably the sort of reaction that anyone might reasonably have. This action is supported by reporting the private thoughts that would be held by someone in that situation ('oh this is my real dad kind of stuff you': 1B/lines 1-8). Reported private thoughts are discursive resources which provide speakers with a way of authentically projecting how a situation would appear to others (Barnes \& Moss, 2007). It sets up Y's expressed course of action (in 1A) of 
resisting seeing her biological father because of her step father's emotional reaction, as something anomalous and accountable, that is as the course of action which is not the 'easy' way to go about things.

A second feature of reported thoughts is that they often form the first component of a contrast structure so that the reported thought acts as the first part which is contrasted with a second thought or experience. In turn this organisation attends to the authenticity of what is constructed as the actual experience in the second part. This contrast is developed collaboratively by T1 who elaborates the 'actual' thoughts of the young person (1B/lines 10-24). Y;s actual thoughts are contextualised through the first part of the contrast structure which identifies the 'normal' or 'easy' way of reacting. T1 constructs a highly positive account of Y's experience and motivation (line 10: thoughtful; line 23-24: thinking about his feelings too).The inference available from T2's version is complementary to $Y$ in that she has resisted the 'easy' course out of consideration for her step-father's feelings.

This part of the RTP also echoes terms used in the main session; "Overprotective" and "strict" were words used together in the main session. In the second version they act as an anchor for the extension of the main session therapist intervention, establishing the authenticity of the therapist's re-working of the talk. In addition, aspects of the main session talk are extended and intensified; thus "she's also been >very angry with err Dad<" (line 12) echoes the main session talk, (1A/lines 11-12) "even tho' sometimes you're fed up with 'im"). This extends this original talk by using "very angry" (rather than the less intense "fed up" from the main session) providing a greater contrast within the second version, between "thoughtful" and "angry". 
Thirdly, T2 shifts the footing of the inferences available from these observations so that knowledge about the stepfather's love and care for $\mathrm{Y}$ is now something known by $Y$ in the first instance. In the main session this knowledge was identified by the therapist (1A/lines 10-11: 'so you must know that he cares about you very much') and attributed to $\mathrm{Y}$ as something accountably evident to her though not necessarily known to her. In the RTP, this understanding of her step-father is shifted as something that the therapist has discerned in $\mathrm{Y}$ and thus known to $\mathrm{Y}$ all along.

Finally, this section of the of the RTP is concluded with a strong sense of agreement between the two therapists. They have collaboratively produced a contrast structure and as the extract ends T2 strongly endorses T1's claims about the state of mind of $\mathrm{Y}$.

The upshot of this RTP reworking of the main session talk, is to reinforce and extend the positivity formulated by the therapist in the main session as a collaboratively accomplished and authoritative version of relations within the family and specifically between $\mathrm{Y}$ and her step-father. Second, by reinforcing the positive nature of relations, it implies that the barriers to a course of action that $Y$ originally resisted are less salient. Moreover, this analysis shows how one of the key elements of the family therapy SIK is manifested. Explicitly revisiting the problem makes clear to all participants that a hopeful outlook can stand in contrast to family problems. The main session intervention and second version work together to publically transform family members stated feelings from internal negative emotions ("she's also been very angry", "he's over-protective", "he's strict") to an external, demonstrated hopeful portrayal of the two family members in relation to each other ("he loves her"/ "thinking about his feelings too"). 


\section{Excerpt 2}

\section{Extending the basis of hope in a second version}

Second versions also develop and extend the hopeful content of main session therapist interventions. The following paired excerpt shows a return to a main session where $C$ discussed his angry and blaming feelings towards his mother. The talk at the end of the main session excerpt by the family therapist placed a hopeful interpretation on C's ability to express his feelings and K's (his mother's) tolerance of this. 
Family 2 Paired Talk, Main Session and Reflecting K = Parent (Katherine), C = Young Person (Harry), T1 = Family Therapist 1, T2 = Family Therapist 2, T3= Family Therapist 3

\section{A Main Session Therapist Intervention}

2B Reflecting/Second Version

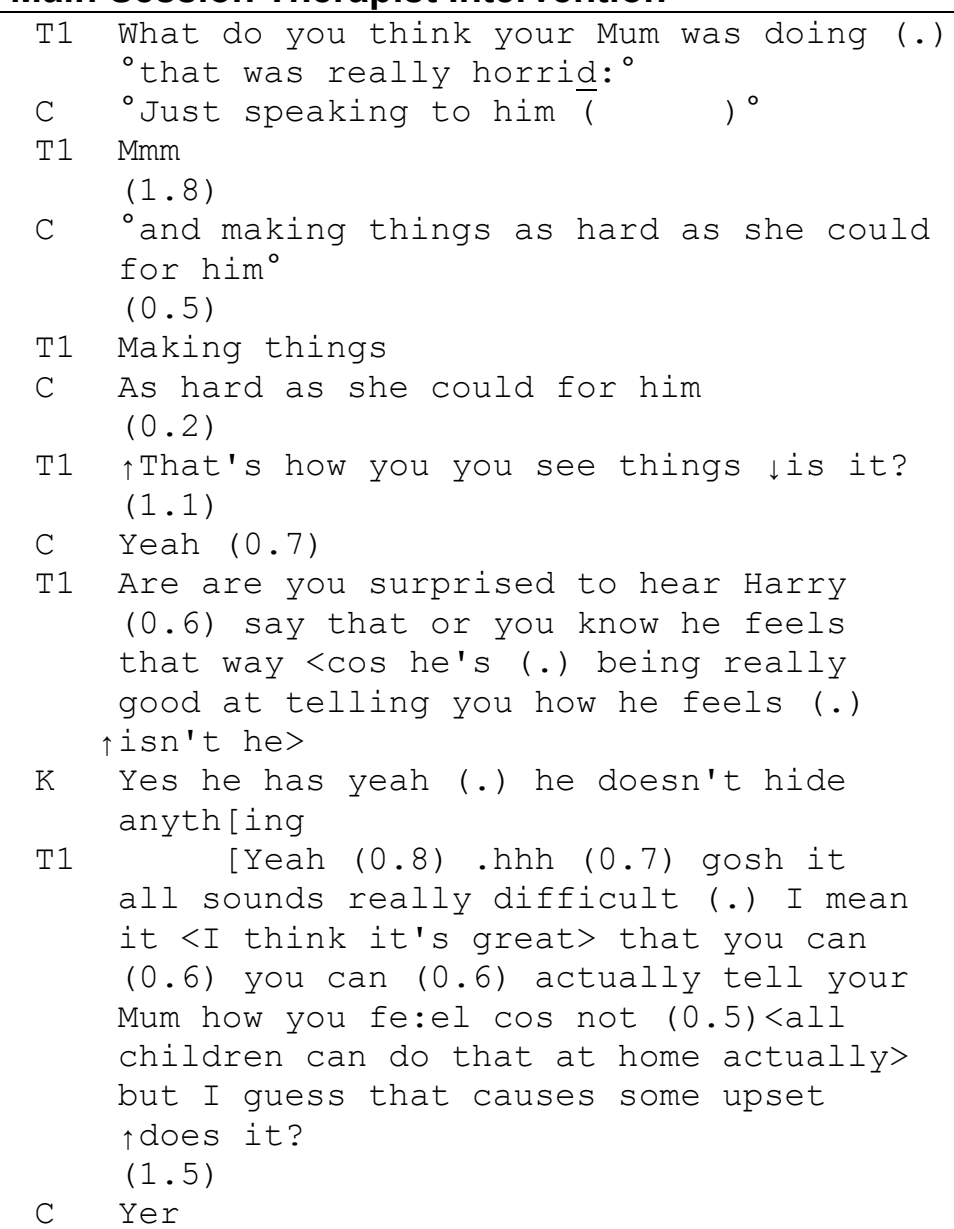

T2 Umm (0.2) $\bullet$ hh $(0.8)$

1 T2 Umm (0.2) •hh (0.8) but (.) I I've been very

2 impresssed really impress:sed by how

Katherines (0.5) allowed him to say how angry he is with 'er

(1.0)

T3 Yeah

T2 how much he thinks she's $\downarrow$ got it wrong it's her $\uparrow$ fault (0.4) um cos it must be so painful $(0.5)$

10 T3 Mmm

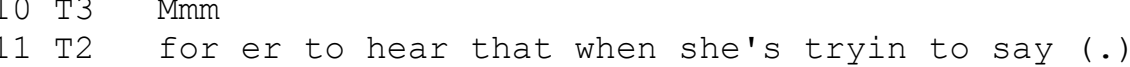
that well (0.3) actually Harry <I'm sorry but your Dad $>(0.8)$ hhh $\uparrow$ scared me (0.6) y'know some of the time any and I was scared about what he did (.) do to some of you

Umm

and $y^{\prime}$ know and n' Harry saying (0.5) no you're making it all up $(0.2)$ is

Umm

sort of ${ }^{\circ}$ you $\mathrm{know}^{\circ}$

$(0.4)$

Umm

umm (1.0) but (.) he's really (0.6) she's really allowed him to say I think y'know I think ssh

(0.2) that (.) just shows to me how much she really loves $(0.6)$

$\mathrm{Umm}$

her her boy $(0.2)$ and it's ve:ry hard 'when your been $(0.6)$ y'know $\downarrow$ when it's been ${ }^{\circ} \uparrow$ thrown back at you (1.0) umm $(0.7)$ like that $(0.2)$ 
This second version demonstrates a hopeful extension to the main session therapist intervention in the following ways

i. The hopeful nature of expressing feelings within the family is revisited

ii. K's role as a loving parent is developed and expanded by foregrounding the relationship between $\mathrm{K}$ and her son

iii. Reciprocity is developed by the therapists which demonstrates an absence of blame (re-worked as an misunderstanding based on absence of facts) and suggests a route forward for the family

As with Extract 1, the main session talk displays the therapist's orientation to transforming potentially difficult and conflictual family relationships into evidence of positive basis to relationships. We see in $2 \mathrm{~A}$ at lines $17-18$ and $21-16$, the therapist selecting particular aspects of the talk up to that point and explicitly identifying how they form the basis for honest communication within between the son and the mother. This positive transformation is further developed in the reflecting session (2B).

At the start of this extract a link is made to the main session assessment $(2 \mathrm{~A} /$ lines 22-24 "I think it's great that you can that you can actually tell your Mum how you feel'). The positive aspects of K's acceptance of her sons angry position is explained by T2, "by how Katherine's (0.5) allowed him to say how angry he is with 'er". This links to the main session where the family therapist selects the relationship between $\mathrm{K}$ and her son (2A/lines 22-27). 2B/lines $3-4$, show $\mathrm{H}$ is 'allowed' to say how angry he is with his mother, this foregrounds the relationship between the two. This turn also headlines K's characteristic as a 'tolerant' parent that echoes the main session therapists turn (2A/ lines 25-26 "Cos not all children can do that at home actually"). In 
common with the main session intervention, the expression of (any) emotion within a family context is interpreted as positive. At 2B/line 6 a 'continuer' - 'yeah', is provided by $\mathrm{T} 3$, this occurs in a sequence of many continuers and shows alignment, which supports the 'structural asymmetry' of the interaction (Stivers, 2008).

At 2B/lines $12-13$, T2 continues by interpreting what $\mathrm{K}$ might want to say to $\mathrm{H}$, “actually Harry<l'm sorry but your Dad> (0.8) hhh $\uparrow$ scared me”. This portrays H's anger as preventing $\mathrm{K}$ from representing her own interpretation of events and paves the way for T2 to elucidate this on her behalf. The narrative voice of this sequence defines and distinguishes the turn that foregrounds the experience of $\mathrm{K}$. This greatly extends the content of the main session. The delivery of reported speech can give insight into the orientation of the person producing the reporting (Stivers, 2008). The talk at $2 \mathrm{~B} /$ /lines $11-15$ is designed to be overheard by $\mathrm{H}$, thus providing an alternative account of his mother's position (despite T3 being the actual physical recipient in the second version telling) this conveys a strong sense of T2's orientation to K's vulnerability, which is unknown to $\mathrm{H}$.

At 2B/line 17, T2 continues with a switch to the third person "and y'know and n' Harry saying (0.5) no you're making it all up". This revisits the main session (2A/ lines 1718 "hes being really good at telling you how he feels isn't he") and foregrounds the relationship between the two. At 2B/line 20, "sort of you know" introduces T2's opinion about H's stance and repair at 2B/lines 23-24 shifts the talk away from H's (problematic) responses to his mother, to her responses to him. T2's ownership of their professional position "I think" (2B/line 24) highlights the following talk as a newsworthy item - "just shows to me how much she really loves her her boy" (2B/lines 25-28). K's role as a loving parent is selected and added to her tolerance of 
H's expression of anger echoing the main session intervention (2A/lines 23-26). This extends the main session talk and transforms it decisively into a caring basis to the relationship between $\mathrm{H}$ and $\mathrm{K}$. This talk is orientated to a family therapy setting, providing an interpretation emphasising the systemic nature of the family through attending to family relationships.

T2 continues by introducing further information about K's position at 2B/lines 29-31, "and it's ve:ry hard ${ }^{\circ}$ when your been (0.6) y'know $\downarrow$ when it's been ${ }^{\circ} \uparrow$ thrown back at you (1.0) umm (0.7) like that". This section refers to the concession outlined at the end of the main session therapist intervention (2A/ lines 26-27 "but I guess that causes some upset at home does it') and again makes this talk accessible to $\mathrm{K}$.

A summary by $\mathrm{T} 2$ (2B/line 34$)$ "so l'm really impressed by that" provides a dramatic end point to this sequence. T2 is affirming his own demonstration of K's position. This shows how the responses and reasons for K's approach are 'storied into being'. 


\section{Discussion}

In the reflecting session family therapists do not need to gain acceptance of their interpretations of the client's experiences from the owners of these experiences (the family members themselves), but instead affirm and align with each other's turns. This enables information from the main session to be freely built on and developed by the therapists in the following ways

1. Prior talk can be revisited and transformed into material that orients to the institutional practice of family therapy

2. Release from negotiating interaction with the family, means the reflecting team are at liberty to bring their knowledge to bear, to categorise and see "relevant significance" in relation to an undisputed corpus of information (Antaki, Barnes \& Leudar, 2005)

3. Specifically, through accessible polyvocality, family therapy interpretations can be 'put on the record' as resources for all participants

The release from talking with the family therapy clients also enables the reflecting team to produce talk about clients in front of them; this accessible polyvocality is a powerful resource to demonstrate an alternative view of family problems by reflecting team therapists.

The recognisability of a second version of the main session reworking of client talk is achieved through its design. Sacks (1992) discusses 'topic affinity' to express the reciprocal nature of continued talk about a specific topic. This makes clear that although the first version of talk was in itself a complete version it can in fact be returned to and elaborated on. Removal of professional cautiousness in the 
reflecting team, (that is required when talking directly to clients), allows greater extension of concepts and ideas that feature in main session.

In second versions, entry devices (Arminen, 2004) introduce information from main session therapist interventions. This can take the form of introducing a prior topic with a positive connotation "err very thoughtful" (1B/ line 10) or a positive change of perspective "I've been very impressed" (2B/ lines 1-2). In addition, entry into second versions can take the form of an upshot from the prior talk, "it's just so easy to go rushing off" (1B/ line 1). Through these mechanisms, family therapists make a clear connection between the second version and the prior therapist intervention. To show allegiance a narrative stance is taken which speaks on behalf of other family members "I'm sorry but your Dad scared me" (2B/lines 12-13). Talk is also ascribed to individual family members to extend and demonstrate the points being made, "Harry saying no you're making it all up" (2B/ lines 17-18). This does the work of making the therapist's versions more accessible to the family members in addition to establishing the therapists as having an understanding of specific family dynamics.

In second versions, main session discussion is systematically represented in a way that orientates talk to the institutional context of family therapy. The positive connotation of the main session talk is revisited and is extended in the second version to include further positive interpretation. This can take the form of a final dramatic point which projects some new information into the second version to support a hopeful outlook, for example, "and returns that by thinking about his feelings too" (1B/ lines 23-24) or "just shows to me how much she really loves her boy" (2B/ lines 25-28). 
Second versions expressed as accessible polyvocality demonstrate hopeful outcomes for the overhearing audience. To achieve this they educate the audience (family members) about appropriate perspectives and approaches to interpersonal family relationships. In all cases second versions move the talk a long way from the initial troubles telling, contained in the main session.

\section{Conclusion}

This paper has shown that therapist interventions and second versions do specific work in demonstrating and building hope within family therapy.

This research indicates that reworking main session client talk and RTP second versions are influential in the family therapy therapeutic process. In main session talk at least three transformations of prior talk can be seen to be taking place, deletion of negative and introspective positions, selection of aspects which place the individual in relation to others and transformation to demonstrate a positive connotation. In RTP second versions hopeful elements are extended and developed by the family therapists, resulting in a projected resolution. The accessible polyvocality of the reflecting session means progress toward a hopeful outcome is demonstrated and witnessed by other therapists and the family. This models the 'correct' approach to family problems and educates family members about their roles in achieving this.

A conversation analysis approach has the potential to enable an examination of the work of family therapy based on the meanings which are created and reinforced in family therapy sessions themselves. Family therapy sessions are routinely video recorded to provide a resource for families and therapist development and supervision. A further use of these recordings could be the examination of the 
creation of meaning in talk to further elucidate how concepts implicit in family therapy are talked into being.

\section{References}

Anderson, T. (1987). The reflecting team: dialogue and meta-dialogue in clinical work. Family Process, 26, 415-428.

Antaki, C., \& Wetherell, M. (1999). Show Concessions. Discourse Studies, 1(1), 727.

Antaki, C., Barnes, R., \& Leudar, I. (2005). Diagnostic Formulations in Psychotherapy. Discourse Studies, 7(6), 1-21.

Arminen, I. (2004). Second stories: the salience of interpersonal communication for mutual help in Alcoholics Anonymous. Journal of Pragmatics, 36, 319-347.

Flaskas, C. (2007). Holding Hope \& Hopelessness: therapeutic engagements with the balance of hope. Journal of Family Therapy, 29, 186-202.

Heritage, J. (1985). Analyzing News Interviews: Aspects of the Production of Talk for an Overhearing Audience. In T. A. Van Dijk, Handbook of Discourse Analysis Volume 3 Discourse and Dialogue (pp. 95-116). London: Academic Press.

Heritage, J. C., \& Watson, D. R. (1979). Formulations as Conversational Objects. In G. Psathos, Everyday language: Studies in ethnomethodology (pp. 123-162). New York: Irvington Publishers Inc.

Hutchby, I. (2005). "Active Listening": Formulations and the Elicitation of Feelings Talk in Child Counselling. Research on Language \& Social Interaction, 38(3), 303-329. 
Hutchby, I., \& Wooffitt, R. (2008). Conversation Analysis. Cambridge: Polity Press.

Jefferson, G. (2004). Glossary of transcript symbols with an introduction. In G. H. Lerner, Conversation Analysis: Studies from the First Generation (pp. 13-31). Philadelphia: John Benjamins Publishing Company.

Jones, E. (1993). Family Systems Therapy. Chichester: John Wiley \& Sons Ltd.

Leech, G., Cruickshank, B., \& Ivanic, R. (2004). An A-Z of English Grammar and Usage. Harlow, Essex: Longman.

Perakyla, A., \& Silverman, D. (1991). Owning experience: Describing the experience of other persons. Interdisciplinary Journal for the Study of Discourse, 11(3), $441-480$.

Perakyla, A., \& Vehvilainen, S. (2003). Conversation analysis and the professional stocks of interactional knowledge. Discourse and Society, 14(6), 727-750.

Sacks, H. (1992a). Lectures on Conversation . Cambridge: Blackwell.

Sidnell, J. (2010). Conversation Analysis: A Introduction. Chichester, West Sussex: Wiley-Blackwell.

Snyder, C. R. (2002). Hope Theory: Rainbows in the Mind. Psychological Inquiry, 13, 249-275.

Stivers, T. (2008). Stance, Alignment, and Affiliation During Storytelling: When Nodding is a Token of Affiliation. Research on Language and Social Interaction, 41(1), 31-57. 
Ward, D. B., \& Wampler, K. S. (2009). Moving up the Continuum of Hope: Developing a theory of hope and understanding its influence in couples therapy. Journal of Marital \& Family Therapy, 36, 212-228.

Weingarten, K. (2010). Reasonable Hope: Construct, clinical applications and supports. Family Process, 49, 5-25.

Willott, S., Hatton, T., \& Oyebode, J. (2010). Reflecting Team Processes in Family Therapy: A search for research. Journal of Family Therapy, 5(11), 1-24. 
A left bracket indicates point of overlap onset

A right bracket indicates the point at which two overlapping utterances end

$=\quad$ Equal sign indicates no break or gap

A pair of equal signs one at the end of one line and one at the beginning of the next indicate no break between the two lines

(0.0) Numbers in parentheses indicate elapsed time by tenths of seconds

(.) A dot in parentheses indicates a brief interval (approx a tenth of a second) within or between utterances

Underscoring indicates some form of stress via pitch or volume. A short underscore indicates lighter stress than a long underscore
\end{abstract}

Underscoring with a broken line indicates a trailing off or increasingly quiet end to the utterance

::: Colons indicate prolongation of the immediately prior sound. The longer the row of colons the longer the prolongation

$\uparrow \downarrow \quad$ Arrows indicate shifts into high or low pitch

WORD Uppercase indicates loud sounds relative to the surrounding talk

${ }^{\circ}$ word $^{\circ} \quad$ Degree signs bracketing an utterance or part utterance indicate soft sounds relative to the surrounding talk

$\quad>\quad$ Right left carats bracketing an utterance indicate that the bracketed utterance is speeded up relative to the surrounding talk

<> $\quad$ Left right carats bracketing an utterance indicate that the bracketed utterance is slowed down relative to the surrounding talk

.hhh A dot prefixed row of 'hhh's' indicates an in breath. Without the dot this indicates an out breath

wohhrd A row of 'hhh's' within a word indicates breathiness

Hehheh, Indicates laughter huh huh

(word) Parenthesised works and speaker designations are dubious or unclear

( ) Empty parentheses indicate the transcriber was unable to understand what was said. The length of the parenthesised space indicates the length of this talk

(()) Double parentheses contain transcribers descriptions

(Source adapted from Jefferson, 2004) 